\title{
CATALISADORES SUPORTADOS EM ZEÓLITA NaY NA DEGRADAÇÃO DE CORANTE TÊXTIL
}

\author{
K. R. PICCOLI, M. H. N. O. SCALIANTE, N. R. C. FERNANDES-MACHADO \\ Universidade Estadual de Maringá, Departamento de Engenharia Química \\ E-mail para contato: karenrpiccoli@gmail.com; nadia@deq.uem.br
}

\begin{abstract}
RESUMO - Sabe-se que o efluente de indústria têxtil é de difícil tratamento por meios tradicionais, pois além de possuir uma alta demanda química de oxigênio, é também fortemente colorido e com alta toxidez. Em função desta dificuldade encontrada, os processos de oxidação avançada (POAs), em particular a fotocatálise heterogênea, se mostraram métodos promissores para a remoção de poluentes orgânicos de efluentes têxteis. Neste trabalho será apresentada a aplicação da fotocatálise heterogênea no tratamento de efluente têxtil sintético (solução de corante Azul Reativo 250 (RB250) a 10 e 100 mg.L.-1), utilizando radiação artificial UV, potência de $250 \mathrm{~W}$, durante $5 \mathrm{~h}$. Os catalisadores utilizados foram sintetizados com $2,5 \%, 5 \%$ e $10 \%(\mathrm{~m} / \mathrm{m})$ de $\mathrm{ZnO}, \mathrm{Nb}_{2} \mathrm{O}_{5}$ e $\mathrm{TiO}_{2}$ suportados em zeólita $\mathrm{NaY}$ comercial por impregnação úmida. A degradação fotocatalítica será acompanhada por descoloração da solução por espectroscopia de absorção no visível.
\end{abstract}

\section{INTRODUÇÃO}

Os corantes fazem parte de um grupo de materiais chamados colorantes que são caracterizados por absorverem luz na região do visível (350 a $760 \mathrm{~nm})$. São compostos orgânicos capazes de colorir substratos têxteis ou não têxteis, em condições de processos préestabelecidos (ZOLLINGER, 1991). A poluição de corpos d'água com estes compostos provoca, além de poluição visual, alterações nos ciclos biológicos, afetando principalmente processos fotossintéticos.

Para controlar a poluição gerada pelo descarte de efluentes líquidos têxteis, muitas indústrias utilizam técnicas baseadas em métodos físico-químicos seguidos de processo biológico que apresentam também alguns inconvenientes: o primeiro tem a necessidade de requerer outros métodos subsequentes para tratar os resíduos gerados, assim, apenas transfere o contaminante da fase líquida para a fase sólida. Já o processo biológico, mesmo sendo um método ecologicamente correto, pode se mostrar ineficiente para a completa remoção de cor e degradação de compostos tóxicos (LEDAKOWICZ et al., 2000).

A fotocatálise heterogênea, dentre outras técnicas, é estudada atualmente como um tratamento complementar, por ser capaz de mineralizar materiais que não são eliminados pelos processos tradicionais (FERNANDES-MACHADO, 2005). No entanto, apesar dos catalisadores em nanopartículas mostrarem uma eficiência considerável nos tratamentos de fotocatálise, o seu pequeno tamanho é um dos principais problemas no tratamento de efluente, 
pois são de difícil filtração e recuperação. Com isso, recentes pesquisas têm sido direcionadas para a impregnação dos catalisadores em suportes adequados (SOBANA e SWAMINATHAN, 2008).

As zeólitas são fortes candidatas a suportes catalíticos, devido às suas características, tais como: estabilidade; elevado volume de poros; propriedade adsorvente e a regularidade de sua estrutura de poros, o que confere ao catalisador suportado porosidade e resistência mecânica (ALVER e METIN, 2012). Neste contexto, a consolidação da tecnologia de tratamento de efluentes hídricos por fotocatálise depende fundamentalmente do desenvolvimento do catalisador apropriado.

Assim, a fotocatálise heterogênea mostra-se como uma alternativa viável de minimização dos efeitos ambientais negativos causados pela indústria têxtil. Desta forma, neste trabalho foi estudada a atividade de fotocatalisadores imobilizados na degradação/mineralização fotocatalítica do corante azul reativo C.I. 250, avaliando também a influência do fotocatalisador: $\mathrm{ZnO}, \mathrm{TiO}_{2}$ e $\mathrm{Nb}_{2} \mathrm{O}_{5}$ impregnados em zeólita $\mathrm{NaY}$, a influência da concentração de corante e a influência do teor de fotocatalisadores impregnados.

\section{METODOLOGIA}

Os fotocatalisadores $\mathrm{Nb}_{2} \mathrm{O}_{5} / \mathrm{NaY}, \mathrm{TiO}_{2} / \mathrm{NaY}$ e $\mathrm{ZnO} / \mathrm{NaY}$, nas proporções de $2,5 \%, 5 \%$ e $10 \%$ cada um deles, foram sintetizados por impregnação úmida com o catalisador disperso com água em ultrassom e posterior secagem em rota-evaporador sobre o suporte. Os catalisadores foram granulados, selecionando-se grãos entre 0,85 e 1,00 mm. Foram então calcinados a $500^{\circ} \mathrm{C} / 5 \mathrm{~h}$. Os catalisadores utilizados foram caracterizados por Difração de Raios X (DRX), Ponto de Carga Nula e Dessorção à Temperatura Programada de Amônia $\left(\mathrm{DTP}-\mathrm{NH}_{3}\right)$.

$\mathrm{Na}$ análise de difração de raios-X utilizou-se o difratômetro de Raios-X Shimadzu modelo XRD6000, tubo de $\mathrm{Cu}$ em modo 2teta com irradiação $\mathrm{CuK} \alpha$, tensão $30 \mathrm{kV}$ e $10 \mathrm{~mA}$, velocidade $2^{\circ} / \mathrm{min}$, intensidade de $2000 \mathrm{cps}$. Os difratogramas foram analisados com o auxílio do banco de dados do Software Xpert Score.

Para o ponto de carga nula, a seguinte metodologia foi adotada: $200 \mathrm{mg}$ de cada catalisador disperso em $50 \mathrm{~mL}$ de água deionizada. Repetiu-se o mesmo procedimento utilizando $50 \mathrm{~mL}$ de solução de cloreto de potássio $(\mathrm{KCl}) 1 \mathrm{~mol} / \mathrm{L}$. Determinou-se o $\mathrm{pH}$ das duas soluções após agitação por 15 min. Os valores de ponto de carga zero são obtidos através da equação de Keng e Uehara, Equação 1.

$$
p c z=2 p H(K C l)-p H(a ́ g u a)
$$

A análise de Dessorção à Temperatura Programa de Amônia $\left(\mathrm{DTP}-\mathrm{NH}_{3}\right)$ teve como objetivo identificar e quantificar a acidez dos catalisadores. Foi realizada no equipamento CHEMBET 3000 da QuantaChrome Instruments.

Os testes fotocatalíticos foram realizados com $1 \mathrm{~g} / \mathrm{L}$ de concentração de catalisador. Inicialmente a solução ficou em contato com o catalisador no escuro, por $1 \mathrm{~h}$ para uma possível adsorção do corante no catalisador, seguida de $5 \mathrm{~h}$ de irradiação. O sistema de reação 


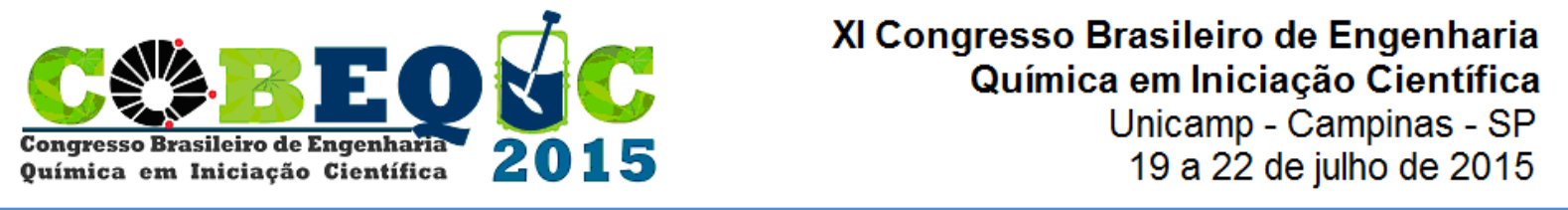

foi formado por um reator de $500 \mathrm{~mL}$ de volume de corante sintético Azul Reativo C.I. $250 \mathrm{na}$ concentração de $10 \mathrm{mg} . \mathrm{L}^{-1}$, equipado com um agitador magnético e um controlador de temperatura. A radiação foi fornecida por uma lâmpada de $250 \mathrm{~W}$ (EMPALUX), sem bulbo para obter a radiação UV, preferencialmente. A atividade catalítica foi avaliada em termos de redução de absorção. A absorbância foi medida a $617 \mathrm{~nm}$ (HACH DR5000 espectrofotômetro), correspondente ao máximo de absorção da corante.

\section{RESULTADOS}

\subsection{Caracterização dos catalisadores}

As análises de difração de raios-X foram realizadas com a finalidade de identificar as fases cristalinas presentes nas amostras. Os difratogramas foram analisados com o auxílio do banco de dados do Software Xpert Score, como pode ser visualizado na Figura 1, referente ao difratograma do $\mathrm{Nb}_{2} \mathrm{O}_{5} / \mathrm{NaY}$.

Figura 1 - Difratograma de Raios-X do óxido de nióbio suportado na zeólita $\mathrm{NaY}$.

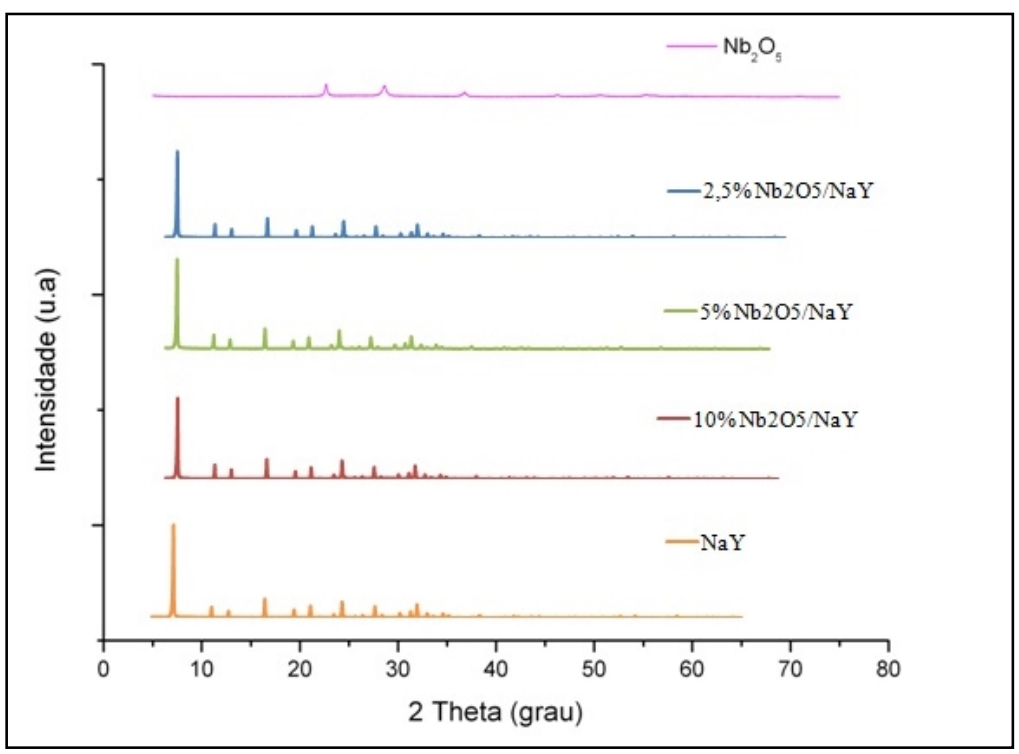

De uma forma geral, verifica-se que os métodos utilizados para obtenção dos catalisadores preservaram a estrutura característica da zeólita, quando comparada com o difratograma da zeólita $\mathrm{NaY}$ de partida. No entanto, não foi possível detectar picos de $\mathrm{ZnO}$, $\mathrm{TiO}_{2}$ e $\mathrm{Nb}_{2} \mathrm{O}_{5}$ impregnados em NaY. Os resultados da análise Dessorção à Temperatura Programa de Amônia (DTP-NH$)$ estão apresentados na Tabela 1. Nota-se que todos os catalisadores apresentam acidez, característica dos óxidos impregnados, com os catalisadores com $\mathrm{Nb}_{2} \mathrm{O}_{5}$ os com maior acidez. A acidez aumentou com o aumento do teor de óxidos impregnados. A temperatura de máxima dessorção indica sítios fracos com máximo em torno de $250^{\circ} \mathrm{C}$. 
Por fim, o ponto de carga nula pHpcz é o $\mathrm{pH}$ no qual o adsorvente tem uma carga superficial líquida zero. A superfície do adsorvente tem uma carga líquida positiva quando $\mathrm{pH}$ $<\mathrm{pHpcz}$, enquanto que para $\mathrm{pH}>\mathrm{pHpcz}$ a superfície possui uma carga líquida negativa.

Tabela 1 - Resultado da análise de DTP em catalisadores suportados.

\begin{tabular}{cccccc}
\hline Catalisador & Massa $(\mathrm{g})$ & $\begin{array}{c}\text { Volume } \\
\mathrm{NH}_{3}(\mathrm{~mL})\end{array}$ & $\begin{array}{c}\mathrm{mmol}^{2} \\
\mathrm{NH}_{3}\end{array}$ & $\begin{array}{c}\mathrm{mmol} \\
\mathrm{NH}_{3} \mathrm{~g} / \text { cat }\end{array}$ & Temp. pico $\left({ }^{\circ} \mathrm{C}\right)$ \\
\hline $2,5 \% \mathrm{Nb}_{2} \mathrm{O}_{5} / \mathrm{NaY}$ & 0,202 & 6,4445558 & 0,26852 & 1,32932 & 279,1 \\
$5 \% \mathrm{Nb}_{2} \mathrm{O}_{5} / \mathrm{NaY}$ & 0,202 & 5,7399552 & 0,23916 & 1,18398 & 267,6 \\
$10 \% \mathrm{Nb}_{2} \mathrm{O}_{5} / \mathrm{NaY}$ & 0,218 & 4,4795545 & 0,18665 & 0,85618 & 239,7 \\
$2,5 \% \mathrm{TiO}_{2} / \mathrm{NaY}$ & 0,202 & 3,9934915 & 0,1664 & 0,82374 & 252,8 \\
$5 \% \mathrm{TiO}_{2} / \mathrm{NaY}$ & 0,203 & 4,1772802 & 0,17405 & 0,85741 & 262,3 \\
$10 \% \mathrm{TiO}_{2} / \mathrm{NaY}$ & 0,205 & 3,362713 & 0,14011 & 0,68348 & 248,8 \\
$2,5 \% \mathrm{ZnO} / \mathrm{NaY}$ & 0,201 & 3,9437798 & 0,16432 & 0,81753 & 240,5 \\
$5 \% \mathrm{ZnO} / \mathrm{NaY}$ & 0,204 & 4,2112346 & 0,17547 & 0,86014 & 246,1 \\
$10 \% \mathrm{ZnO} / \mathrm{NaY}$ & 0,201 & 3,6728878 & 0,15304 & 0,76138 & 243,5 \\
\hline
\end{tabular}

No processo fotocatalítico, a adsorção da matéria orgânica é necessária para que ocorra a interação das moléculas de corante com os catalisadores suportados oxidando-as, no entanto a adsorção não pode ser forte a ponto de sobrecarregar o fotocatalisador. A adsorção forte pode impedir que a energia luminosa alcance os sítios ativos, diminuindo sua eficiência fotocatalítica. A interação do fotocatalisador com a água ou com íons hidróxidos é necessária para a formação do radical hidroxila, que é o agente oxidante que ataca a matéria orgânica. Estima-se que um efluente que tenha $\mathrm{pH}$ próximo do $\mathrm{pHpcz}$ do catalisador favoreça o processo fotocatalítico. A Tabela 2 apresenta os valores do ponto de carga nula dos catalisadores e os valores do $\mathrm{pH}$ da solução de corante com o catalisador, no início do teste, $0 \mathrm{~h}$, antes de ligar a lâmpada, $1 \mathrm{~h}$, e no fim do teste, $6 \mathrm{~h}$. Nota-se que o $\mathrm{pH}$ do meio fica em patamares inferiores aos de carga nula do respectivo catalisador, subindo lentamente com o progresso da reação.

Tabela 2 - Resultados do ponto de carga nula dos catalisadores suportados.

\begin{tabular}{ccccc}
\hline Catalisador & pHpcz & Amostra $0 \mathrm{~h}$ & Amostra $1 \mathrm{~h}$ & Amostra $6 \mathrm{~h}$ \\
\hline $2,5 \% \mathrm{Nb}_{2} \mathrm{O}_{5} / \mathrm{NaY}$ & 7,38 & 6,08 & 6,10 & 6,34 \\
$5 \% \mathrm{Nb}_{2} \mathrm{O}_{5} / \mathrm{NaY}$ & 6,80 & 6,12 & 6,18 & 6,41 \\
$10 \% \mathrm{Nb}_{2} \mathrm{O}_{5} / \mathrm{NaY}$ & 5,41 & 6,24 & 6,22 & 6,42 \\
$2,5 \% \mathrm{TiO}_{2} / \mathrm{NaY}$ & 8,32 & 7,61 & 7,59 & 8,42 \\
$5 \% \mathrm{TiO}_{2} / \mathrm{NaY}$ & 7,55 & 7,47 & 7,38 & 7,40 \\
$10 \% \mathrm{TiO}_{2} / \mathrm{NaY}$ & 6,50 & 7,22 & 7,23 & 7,30 \\
$2,5 \% \mathrm{ZnO} / \mathrm{NaY}$ & 8,13 & 7,34 & 7,32 & 7,46 \\
$5 \% \mathrm{ZnO} / \mathrm{NaY}$ & 8,02 & 7,13 & 7,14 & 7,44 \\
$10 \% \mathrm{ZnO} / \mathrm{NaY}$ & 8,00 & 7,28 & 7,22 & 7,33 \\
\hline
\end{tabular}




\subsection{Testes Fotocatalíticos}

Primeiramente, realizou-se um teste fotocatalítico apenas com o suporte $\mathrm{NaY}$ para uma melhor análise dos catalisadores impregnados neste suporte, Figura 2a. Analisando a degradação do corante utilizando apenas o suporte $\mathrm{NaY}$ vê-se que a quantidade degradada atinge uma razão de C/Co igual a 0,4 , o que implica em uma degradação de aproximadamente $60 \%$, comprovando que a zeólita é capaz de descolorir a solução. Isso confirma a atuação da zeólita em facilitar a fotólise pela área de contato, originando uma função pseudo-catalítica da mesma. Visualmente não foi observado coloração na zeólita. As Figuras 2b, $3 a$ e $3 b$ apresentam os perfis de descoloração ao longo do tempo para os catalisadores impregnados.

Figura 2 - Degradação fotocatalítica do corante sintético a 10 mg.L $\mathrm{L}^{-1}: \mathrm{a}$ - $1 \mathrm{~g} / \mathrm{L}$ de NaY. b $1 \mathrm{~g} / \mathrm{L}$ de $\mathrm{Nb}_{2} \mathrm{O}_{5} / \mathrm{NaY}$

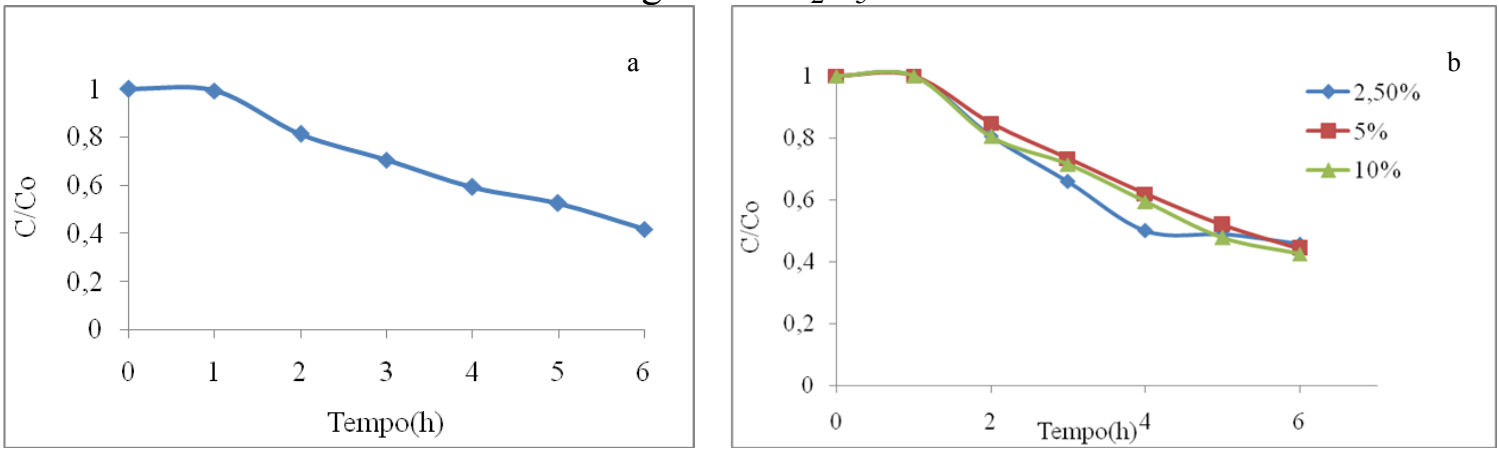

Figura 4 - Degradação fotocatalítica do corante sintético a $10 \mathrm{mg} \cdot \mathrm{L}^{-1}$ : a - $1 \mathrm{~g} / \mathrm{L}$ de $\mathrm{TiO}_{2} / \mathrm{NaY}$; $\mathrm{b}-1 \mathrm{~g} / \mathrm{L}$ de $\mathrm{ZnO} / \mathrm{NaY}$
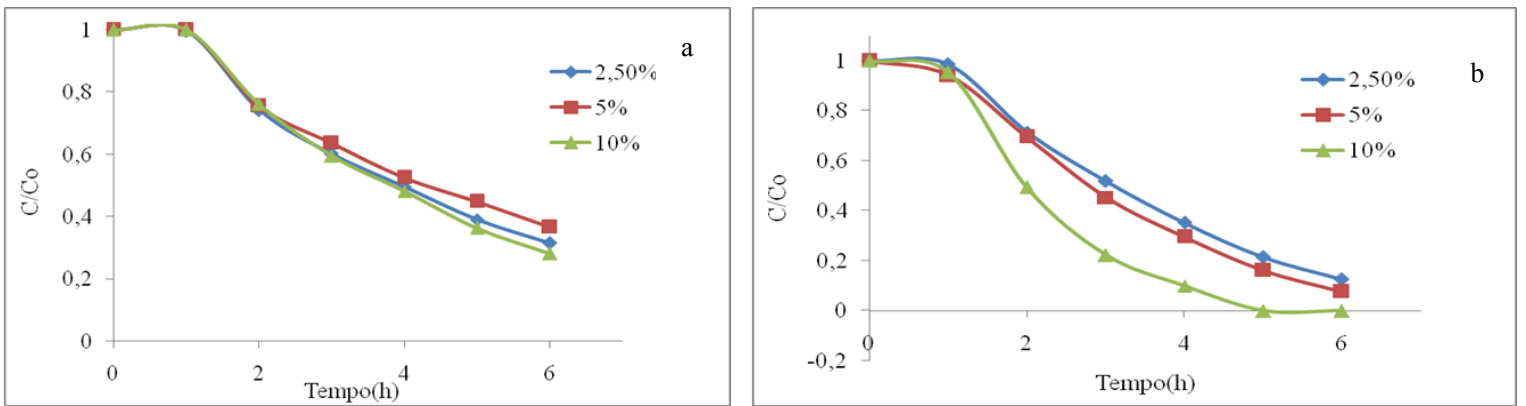

Avaliando os três tipos de catalisadores em diferentes porcentagens $\mathrm{m} / \mathrm{m}$, nota-se que os melhores resultados foram aqueles onde foi empregado óxido de zinco, nomeadamente o catalisador $10 \% \mathrm{ZnO} / \mathrm{NaY}$ que degradou $100 \%$ da solução de corante sintético com apenas $4 \mathrm{~h}$ de fotocatálise. A diferença de atividade dos catalisadores pode ser justificada em parte devido à acidez de cada um, como é o caso do 2,5\% $\mathrm{Nb}_{2} \mathrm{O}_{5} / \mathrm{NaY}$, que é o mais ácido e de menor descoloração do corante, enquanto o catalisador menos ácido apresentando maior degradação. Isso pode ser explicado pelo pH ácido da solução de corante. Deve-se observar também que em todos os testes não foi observada adsorção de corante na primeira hora de 


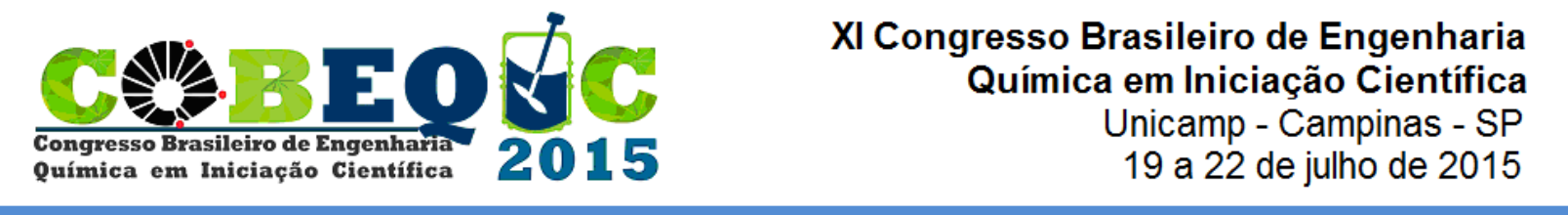

teste, realizado no escuro e que a redução de coloração ocorreu somente pela degradação fotocatalítica.

\section{CONCLUSÃO}

Foi demonstrado que a fotocatálise é um processo terciário promissor para o tratamento de efluentes da indústria têxtil, assim mostra-se como uma alternativa viável de minimização dos efeitos ambientais causados pelo corante. O método de preparação dos catalisadores, impregnação úmida dos óxidos $\mathrm{ZnO}, \mathrm{TiO}_{2}$ e $\mathrm{Nb}_{2} \mathrm{O}_{5}$ em zeólita $\mathrm{NaY}$, geraram fotocatalisadores com alta atividade catalítica, obtendo-se resultados promissores nos testes fotocatalíticos com corante sintético. Foi evidenciado que o óxido de zinco suportado em zeólita $\mathrm{NaY}$, apresenta maior eficiência na degradação do corante. A impregnação dos fotocatalisadores em zeólita $\mathrm{NaY}$ gera catalisadores ativos e viabiliza sua reutilização, uma vez que não se formam partículas dispersas no meio, podendo-se empregar grãos maiores de fácil separação.

\section{REFERÊNCIAS}

ALVER, E.; METIN, A. U. Anionic dye removal from aqueous solutions using modified zeolite: Adsorption kinetics and isotherm studies. Chem. Eng. J., 2012, 200-202: 59-67.

FERNANDES-MACHADO, N.R.C., SANTANA, V.S., Influence of thermal treatment on the structure and photocatalytic activity of $\mathrm{TiO}_{2}$ P25, Catal. Today, 2005, V. 107-108, 595601.

KENG J.C.W.; UEHARA, G. Proceedings of Soil Crop Science Society of Florida, 1974, v. 33, p.119-126.

LEDAKOWICZ, S.; SOLECKA, M.; ZYLLA, R. Biodegradation, decolourisation and detoxication of textile wastewater enhanced by advanced oxidation processes. Journal of Biotech., 2000, 89: 175-184.

SOBANA, N.; SWAMINATHAN, M. The effect of operational parameters on the photocatalytic degradation of acid red 18 by ZnO. Separation and Purification Technology, 2008, 56: 101-107.

ZOLLINGER, H. R. Color Chemistry: Syntheses, properties and applications of organic dyes and pigments. Wiley -VCH: Weinheim, New York, $2^{\text {nd }}$ Edition, 1991. 